\title{
From nostalgia for the recent past and beyond : The temporal frames of recalled consumption experiences
}

\section{Ryynanen, Toni}

2018-01

Ryynanen , T \& Heinonen , V 2018 , ' From nostalgia for the recent past and beyond: The temporal frames of recalled consumption experiences ' , International Journal of Consumer Studies , vol. 42 , no. 1 , pp. 186-194 . https://doi.org/10.1111/ijcs.12398

http://hdl.handle.net/10138/237030

https://doi.org/10.1111/ijcs.12398

other

publishedVersion

Downloaded from Helda, University of Helsinki institutional repository.

This is an electronic reprint of the original article.

This reprint may differ from the original in pagination and typographic detail.

Please cite the original version. 


\section{From nostalgia for the recent past and beyond: The temporal frames of recalled consumption experiences}

\section{Toni Ryynänen ${ }^{1}$ () | Visa Heinonen²}

${ }^{1}$ University of Helsinki, Ruralia Institute, Lönnrotinkatu 7, Mikkeli 50100, Finland

${ }^{2}$ University of Helsinki, Department of Economics and Management, University of Helsinki, Latokartanonkaari 5, 00014

Helsinki, Finland

\section{Correspondence}

Toni Ryynänen, University of Helsinki, Ruralia Institute, Lönnrotinkatu 7, Mikkeli 50100, Finland.

Email: toni.ryynanen@helsinki.fi

\section{Funding information}

Foundation for Economic Education, Grant/ Award Number: 10-5611

\begin{abstract}
Studies of nostalgia are one of the research subfields of recalled consumption experiences. In addition to the nostalgic recall, the consumers' remembered experiences situate in other temporal frames, a theme rarely touched in the extant research. The aim of this research was to examine the differences between nostalgic and other recalled consumption experiences by identifying and analysing the characteristics of the temporal frames. The data set for this task comprised 480 descriptions of consumers' experiences involving an everyday consumer object. An interpretive approach was utilized to analyse the temporal frames. The results of the study indicate that the consumers described their memories in four temporal structures. These are the strong nostalgia from childhood, light nostalgia from youth, descriptions of recent past and memories linked to consumption practices and traditions that will be fostered in the future. The article proposes a conceptual framework describing the temporal frames of consumers' remembered consumption experiences that opens further avenues for research alongside of nostalgic recall.
\end{abstract}

\section{KEYWORDS}

consumption experience, nostalgia, ordinary objects, remembered experience, temporal frames, temporality

\section{1 | INTRODUCTION}

In the course of the past 35 years, consumption experiences have been established as a subject in the field of consumer research. From the early 1980s, consumption experiences have been established as part of the field of consumer research (see Addis \& Holbrook, 2001; Hirschman \& Holbrook, 1982; Holbrook, 1995, 2006; Holbrook \& Hirschman, 1982). One stream of this research agenda addresses consumers' remembered consumption experiences (Arnould, Price, \& Zinkhan, 2002). Even the term 'experience' is somewhat challenging: it can be understood as 'a noun and a verb and it is used variously to convey the process itself, participating in the activity, the affect or way in which an object, thought or emotion is felt through the senses or the mind, and even the outcome of an experience by way of a skill or learning for example' (Tynan \& McKechnie, 2009, pp. 502-503). Due to these phenomenal and terminological ambiguities experiences are demanding study objects (Carú \& Cova, 2003).

By remembered consumption experience, we refer to the consumers' accumulated knowledge and experiences of the past (e.g., Schmitt,
2010). Some consumption experiences are remembered, but all of them accumulate and are scattered in time. The extant research on recalled consumption experiences has scarcely addressed the question of how people's memories situate temporally. Therefore, purpose of our research was to examine the temporal frames of remembered consumption experiences. The focus is on the question, how recalled experiences involving an ordinary everyday object-a thermos bottle-are temporally framed from the consumers' perspective? We utilize the term "temporal frame" to refer to various temporally structured situations in their lives.

A major research stream under the topic of remembered consumption experiences has examined nostalgia. At the beginning of the 1990s, research interest in nostalgia and nostalgic recall was developing. Consumer researchers have defined nostalgia as 'a preference (general liking, positive attitude or favourable effect) toward experiences associated with objects (people, places or things) that were more common (popular, fashionable or widely circulated) when one was younger (in early adulthood, adolescence, childhood or even before birth)' (Holbrook \& Schindler, 1991, p. 330). However, there is no unambiguous definition 
accepted by the scientific community. Since Davis (1979) many writers have emphasized the bittersweet tone of nostalgia, for example.

Nostalgic recall draws mainly from childhood experiences and it is well-defined in the extant literatures referring to a memorable experience from the distant past. Recalled consumption experiences and the nostalgic context have been utilized by marketing researchers in creating and maintaining product or service imagery for selling purposes: nostalgia has been utilized to construct commodity images for consumers in various contexts (Hamilton \& Wagner, 2014; Higson, 2014; Meyers, 2009; Muehling \& Sprott, 2004; Stern, 1992).

Recalled experiences involving everyday goods are important for the consumers' identities. According to Belk (1990), the studies of time in consumer research have largely ignored the role of possessions in creating and maintaining a sense of past as it is also essential to a sense of identity. Memories of possessions that are valued provide a rich repository of the consumer's past and they act as a stimulus to further recollection. Consumption objects are not just containers or anchors for memories, but they can bring back a rich web of thoughts and feelings (Belk, 1990; Richins, 1994). Everyday products embody, mediate and represent events in the consumers' past that induce strong feelings and recalled experiences in the present moment.

The need to address temporal frames of consumers' recalled experiences arises from four reasons: recalled experiences are often connected to the distant past and nostalgia, but analyses of recent memories are scarce; the characteristics of recalled experiences from the temporal perspective are currently unknown; memories tend to be organized according to life stages which refer to temporal structure of recalled experiences, and there is a need to understand better the temporal frames from the consumers' perspective as the past is utilized increasingly in consumer business. Extending nostalgia theorizing by identifying temporal frames of recalled consumption experiences will reduce the existing gap between nostalgic experiences drawing from the distant past and the recent consumption experiences. Everyday observations suggest that people assign meanings to recalled experiences of the past according to other temporal structures alongside the nostalgic recall. In addition, remembered experiences seem to be organized temporally according to various lived life stages and situations. Understanding better the characteristics of temporally scattered remembered experiences and their connections to the individuals' life situations has a practical meaning as recalling the times past has been an increasingly utilized in business (Hamilton \& Wagner, 2014; Lowenthal, 1985). Therefore, our purpose is to extend the current findings of nostalgia research to a broader context of temporal frames characterizing recalled experiences.

In the next section, the characteristics of nostalgic experiences are discussed. The collected research materials and methods are introduced in Section 3 followed by a Section 4 where we contemplate if the consumers' memories are temporally framed and what characterises these frames. In this section, we extend discussions about nostalgic recall to other temporal frames based on the observations and evidence drawn from the research materials. The last section is reserved for the concluding remarks and the discussions about the limitations of the study.

\section{2 | A REVIEW ON REMEMBERED CONSUMPTION EXPERIENCES AND NOSTALGIA}

A Swiss physician Johannes Hofer first defined the phenomenon of nostalgia (from Greek: nostos-return, algos-suffering or grief) as a medical condition or homesickness he found amongst the Swiss mercenaries sent to the foreign lands (Fuentenebro \& Valiente, 2014; Hofer, 1688 [1934]). Later, the term nostalgia was used to refer to experiences of time and as a personal and cultural practice (Meyers, 2009; Wildschut, Sedikides, Arndt, \& Routledge, 2006). Social scientific research has identified several classifications of nostalgia. Davis (1979) introduced three orders of nostalgia (simple, reflexive and interpreted), Havlena and Holak's (1991) tripartite categorization based on self-experienced nostalgia and those not lived through by the first hand (personal, historical and communal), as well as Baker and Kennedy's (1994) three conditions for nostalgic experiences (real, simulated and collective).

Nostalgia tends to be both disproportionately positive but also bittersweet emotion and attitude experienced towards the past: The past is viewed with both sadness and longing (Davis, 1979; Lowenthal, 1985). Nostalgic recall refers to a defined period of time an individual hope but cannot return (Baker \& Kennedy, 1994; Barrett et al., 2010; Batcho, 2007; Havlena \& Holak, 1991; Holak \& Havlena, 1992; Sedikides, Wildschut, Arndt, \& Routledge, 2008; Sierra \& McQuitty, 2007). Nostalgic memories often involve everyday objects capable of arousing the feelings of warmth and intimacy as Belk's (1990), Stern's (1992), Baker and Kennedy's (1994), Holak and Havlena's (1998) and definitions of nostalgia suggest.

Nostalgic feelings can draw from basically everything a person has experienced (Holbrook \& Schindler, 2003; Schindler \& Holbrook, 2003). These include strong social bonds, meaningful others and momentous life events (Sedikides et al., 2008), the feelings of success or excitement of trying out new things, new consumer goods or starting a new hobby (Holbrook \& Schindler, 2003) and various products from jewellery to cars (Baker \& Kennedy, 1994; Havlena \& Holak, 1991), food products and eating practices (Autio, Collins, Wahlen, \& Anttila, 2013; Dalli \& Romani, 2007; Kauppinen-Räisänen, Gummerus, \& Lehtola, 2013; Kessous \& Roux, 2008; Vignolles \& Pichon, 2014; Zarantonello \& Luomala, 2011) as well as packaging (Ryynänen, Joutsela, \& Heinonen, 2016; Underwood, 2003). Nostalgic meanings seldom rise only from the object itself, but are connected with an individual's experiences with the object, with familiar people and at defined physical places (Hirsch, 1992; Holak \& Havlena, 1998; Holbrook, 1993; Holbrook \& Schindler, 2003; Kessous, 2015; Kessous \& Roux, 2008; Ryynänen et al., 2016; Schindler \& Holbrook, 2003).

According to the extant literature old age and nostalgia proneness increase the tendency to recall nostalgic experiences from the childhood and youth (Havlena \& Holak, 1991). Routledge, Wildschut, Sedikides, and Juhl (2013) (see also Davis, 1979; Wildschut et al., 2006) found that university students reported having the frequent feelings of nostalgia. Age and mere exposure or repeated usage of the object of nostalgia do not seem alone to be sufficient enough to form nostalgic bonding (Holbrook \& Schindler, 2003). Nostalgia is a feeling 
toward the past. People share it as it is experienced across different ages and social, economic and cultural groups (e.g., Hepper et al., 2014; Routledge, Wildschut, Sedikides, Juhl, \& Arndt, 2012; Zhou, Sedikides, Wildschut, \& Gao, 2008).

A key to nostalgic experiences is exposure to an object during childhood or youth years when a person's tastes and preferences develop resulting in a devotion towards an object felt inducing nostalgia later in an individual's life (Schindler \& Holbrook, 1993). According to Kessous and Roux (2008), nostalgic experiences can be associated with single and unique situations or first-time nostalgia which are intensive and emotional or the experiences can be based on continual exposure or long-standing nostalgia. Based on the review, most of the consumers' nostalgic experiences draw temporally from the events encountered during childhood or youth years.

\section{3 | RESEARCH MATERIALS AND METHODS}

Data were collected to explore the nature of temporal frames used in recalled consumption experiences. Studies on consumption experiences have mostly relied on qualitative research materials and analysis methods that draw on observation and narration (Carú et al., 2014). As consumer experiences are practically impossible to observe directly, we utilized the people's a posteriori verbalizations. Methods of data collection that allow people's time to reflect on and recall experiences are more suitable than methods requiring immediate answers in situations that can be perceived as socially pressing (Carú \& Cova, 2008). Informants may have difficulties in articulating their remembered experiences during face-to-face interview situations (e.g., Ryynänen \& Rusko, 2015).

The research materials were collected using a writing assignment open for all over 18-year-old persons living in Finland. The assignment was administered by a Finnish multi-product company Airam Electric Oy Ab that has manufactured thermos bottles (Figure 1) since 1934 and the material collection took place in the 80th production year campaign (2014). The writing assignment was realized with an online webpage that was open from March 4 to November 30, 2014. The

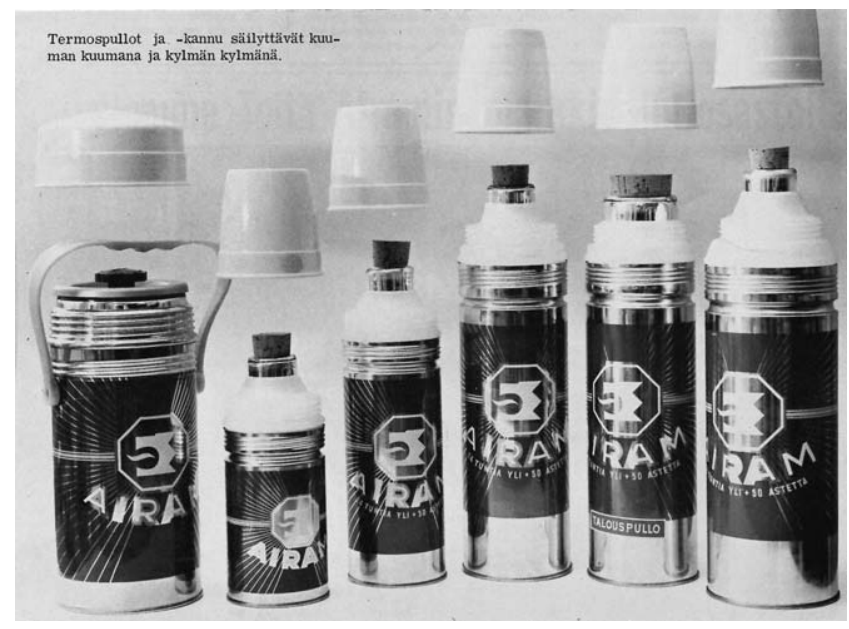

FIGURE 1 Airam thermos bottles in 1963 (source: Airam archives, printed with the permission of Airam Electric Oy $\mathrm{Ab}$ ) company offered monthly product prizes and a travel gift voucher as the main prize in order to encourage participation. The task assigned to the participants was as follows:

What is your story of Airam-thermos? How an Airam-thermos has travelled with you along the way? Is it the best picnic or familiar and safe saviour of a busy morning? Share your memories with us and you may win rewards.

Altogether 1,700 messages were received but most were excluded in preliminary review as they missed analysable experiences or contained product reclamations, development suggestions and general feedback and were therefore unsuitable for the analysis purposes. The described convenience sampling produced a 90 pages long text corpus with altogether 480 analysable writings that fulfilled three conditions: a description involved a thermos bottle, the text addressed an understandable consumption experience, and included an identifiable temporal frame. Written descriptions of the experiences are referred to by their serial number (e.g., 1-480). Participants' background information was not collected since the focus of inquiry was on consumers' remembered experiences.

All of the submitted materials were written in Finnish with the exception of two in Swedish $(88,473)$. The presented quotes were first translated independently by both of the authors and then compared in order to verify that the original meanings did not change during the translation process. The writings varied in length from one sentence to two pages. The collected memories were not treated as either fiction or true and objective descriptions of something that once happened but as sources of information that provide insight into exploring the temporal frames of recalled consumption experiences. The writing assignment allowed the subjective styles of narration, but all of the included writings touched upon the time when experiences were encountered. The oldest experience was in 1943 when the male writer was 13 years old (70). The most recent experience occurred just a day before submitting the writing (399).

An interpretive approach (Holbrook, 1995; Spiggle, 1994; Thompson, Locander, \& Pollio, 1989) was utilized to explore these product-related recalled experiences and their temporal frames. Descriptions of recalled experiences were systematically and individually read through several times. We examined first the experiential and material contexts in order to get the overall picture of the materials reported on Section 4.1. Then, we established how recalled experiences were temporally situated and were able to group the data into four recurring temporal frames. During the last stage, we constructed the characteristic of each temporal frame by asking what constitutes each of the frames.

\section{4 | FINDINGS: THE TEMPORAL FRAMES OF RECALLED EXPERIENCES}

\subsection{Setting the stage: Contexts of recalled experiences involving a thermos bottle}

Before proceeding to explore the temporal frames, we will first set a stage and describe the rich contexts of recalled experiences. The 


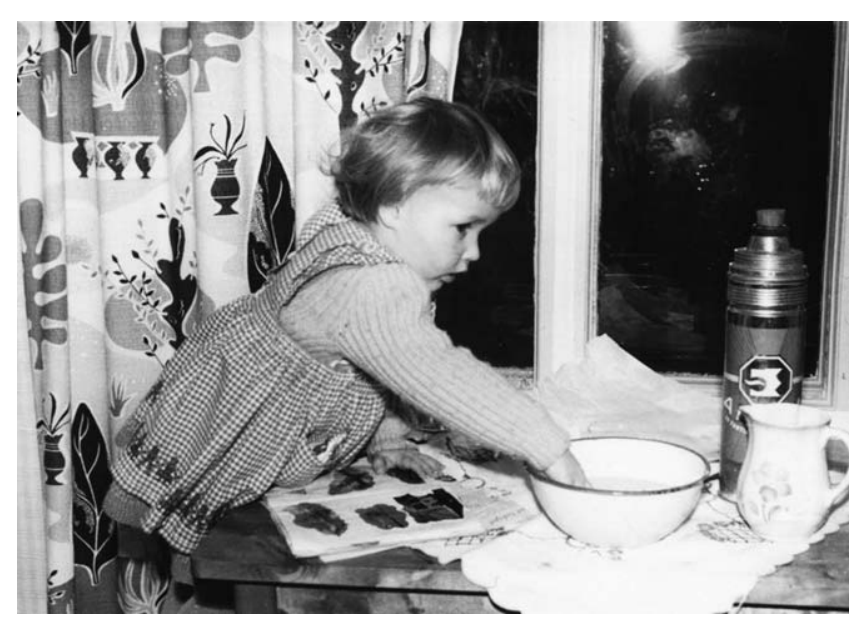

FIGURE 2 Airam thermos bottles in conjunction with other objects at home (source: Airam archives, printed with the permission of Airam Electric Oy Ab)

writers mentioned the physical characteristics and visual cues of the thermos bottles such as the red or red and white colour combinations and the company's logo. Most of them described the materials such as an integral plastic cup, metal casing, inner part of a bottle made of class and a cap made of cork which was later replaced with a plastic cap. Especially the cork cap of old bottles was cherished and the easily breaking inner glass part of the thermos was mentioned as a source for bitter experiences. Writers mentioned complementary products such as packed lunches or food, a rucksack, a greaseproof paper both used in sealing up a thermos cork but also as a sandwich wrappings and a wool sock utilized around a thermos to prevent it from breaking.

Meaningful others were essential sources of experiences as suggested by the reviewed studies. The contexts involving a thermos were related to family gatherings and leisure time (Figures 2 and 3) but described also work contexts summarized in Table 1 on the next page. The number of associated nature experiences reported is noteworthy. This was probably attributable to the examined consumer product, but

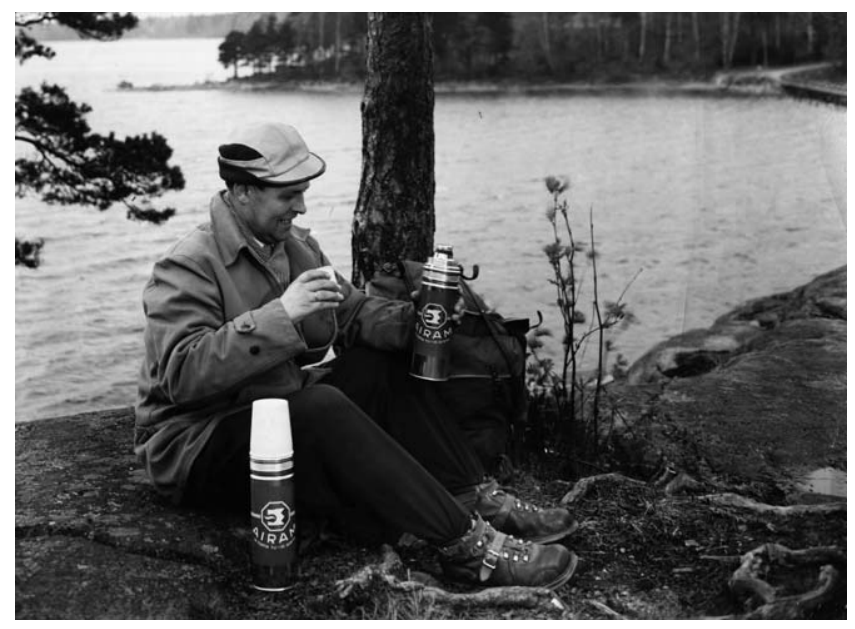

FIGURE 3 Airam thermos bottles in conjunction with other objects during an outing trip (source: Airam archives, printed with the permission of Airam Electric Oy Ab) this finding reflects both the culturally and geographically relevant contexts. Childhood outing memories, a relationship with the nature and food-related themes recurred also in a study of nostalgia among Russian consumers (Holak, Matveev, \& Havlena, 2007) as well as the socio-material practices involving an iconic Soviet-era brand of cheese (Kravets \& Örge, 2010)

The sense of smell (Hirsch, 1992, 2006; Holbrook \& Schindler, 2003) but also taste memories can trigger emotionally charged experiences called the 'Proust phenomenon' (Chu \& Downes, 2000, p. 44). Consumers mentioned smell and taste memories in over 60 separate writings both in the free time and work contexts. Most of the described smell and taste memories can be interpreted as nostalgic and are therefore positive or bittersweet. Coffee, tea or hot chocolate enjoyed from a thermos along with sandwiches are described as tasting better when consumed during the recalled event:

[...] thermoses always bring to my mind hunting and fishing trips with my father when I was a kid. I did not appreciate coffee much at that age, but I had sandwiches and hot chocolate in my own thermos. I can still feel the sweet taste of warm chocolate in my mouth and that nice warming feeling in my stomach, after I had spent a cold and shivering day in the forest! (14)

Most of the experiences and all of the smell and taste memories were connected to pauses and breaks which were mentioned as the peak moments of an event: the moment when provisions were eaten on skiing $(14,202,246,294)$ and on forest trips $(228,296,317,462)$. These breaks were awaited and a thermos was described as a central object of these experiences. The meaning of social and shared experience intensified during the breaks. None of the informants described the activities of skiing or picking berries provoking nostalgia per se. It was the break, the sandwiches and the scent of refreshing coffee enjoyed while sitting on the tree stump in the middle of the wilderness with the loved ones that made the experiences worth remembering for these informants.

\subsection{Strong and light nostalgia: Recalled childhood and youth experiences}

During our examination of context for the written materials and the formation of the temporal frames, it became evident that events encountered during the childhood years were reported nostalgically. We call this temporal frame of recalled experiences from childhood strong nostalgia. By strong we mean that the nostalgic descriptions of the memories were similar to those established in the extant consumer research. These descriptions are nostalgic: they are emotional, connected to events encountered during one's childhood, involve meaningful others and personally important places and are mostly positive or bittersweet descriptions of 'good old times'.

Memories are experienced in the present but they orient to the past. According to our observations, most narratives of strong nostalgia in the materials described childhood events (ages when mentioned 
TABLE 1 Examples of experiential contexts that involve a thermos bottle

\begin{tabular}{|c|c|}
\hline Free time contexts & Work contexts \\
\hline $\begin{array}{l}\text { The trips to nature }(59,145,162,399) \text {, eating provisions at a camp fire }(219,284 \text {, } \\
394)\end{array}$ & A factory worker $(199,138,167)$ \\
\hline Fishing $(4,157,331)$, ice fishing $(8,63,278)$ & A lumberjack $(133,170,293)$, a woods foreman $(120,435)$ \\
\hline Berry picking $(91,228,259,296,317,356,462)$ & A lorry driver $(13,374)$ \\
\hline Vehicle trips: car $(206,226)$, boat $(207,224,250)$, bicycle (103), snowmobile (213) & A teacher $(2,185)$ \\
\hline Skiing $(14,202,225,246,294)$, skating and playing ice hockey $(209,245,272)$ & A biologist working in a field setting (351) \\
\hline Pet and domestic animal-related hobbies $(215,281,306,404)$ & A political party activist (134) \\
\hline Swimming or an experience on a beach $(118,121,449)$ & $\begin{array}{l}\text { Temporary or youth summer jobs }(68,118,191,223,239 \text {, } \\
268,311)\end{array}$ \\
\hline
\end{tabular}

varied from 3 to 14 years old). The informant saw something in a familiar place and was a part of a group of people such as family or relatives. These childhood memories were nostalgic according to extant definitions, and they were positive and took place in pleasing situations:

I was born in December 1960. It was winter in January 1966. I was 5 years and 1 month old. My beloved grandfather came up with an idea that we two would go skiing in spite of the chilly freeze. Grandpa took a red Airam thermos, poured black juice [blackcurrant, an author note] and hot water in. With this, we, children get along the skiing trip. We skied for a while and my face and toes were freezing. Grandpa proposed that now we sat and take a good sip from the thermos. There we sat and enjoyed the hot drink. Then we left cheerfully towards home. Everlasting remembrance for me, which I will never forget. My beloved grandpa is gone, but I have that particular thermos as a reminder of him which I will never give away. (136)

Second, informants reported experiences that happened in their adolescence years (ages when mentioned varied from 15 to around 25 years). When thermos bottle-related experiences encountered during those years were described, examples included hitching with friends (181), the memories of boyfriends (but no girlfriends) (current husband 98, ex-boyfriend 99); studying in high school $(49,96,233)$ and participating in further education after graduation from comprehensive and high school (117, 391, 263, 304). We call this temporal frame of recalled experiences from youth light nostalgia. Some of the experience descriptions are nostalgic in their tone, but different when compared with the strong nostalgia. In all light nostalgia descriptions, the informants were active participants of the described events.

In the light nostalgia temporal frame informants reported an active role. They are doing something by themselves or they describe having control over the events. These experiences include descriptions of doing housework such as washing up a thermos bottle (111), sawing firewood (32) and descriptions of the first jobs (as a lumberjack 110, 123,163 or as a construction worker 183) as described in the next quotation:
As a youngster, I had a thermos bottle when I worked on the sugar beet field. Coffee tasted there the best ever: add some slices of white bread and the enjoyment were totally magnificent. After using my thermos bottle during the summer jobs, I put the bottle away and now it has the pride of place in the cupboard. It has done its work. Maybe somebody needs it someday. (310)

In the quotation, the informant is the main character of the narrative and is an active participant of the described events. Meaningful others typical for childhood nostalgia are missing making this recalled experience an example of light nostalgia.

\subsection{Recent past and practices for the future}

The temporal frames linked to childhood and youth ages' experiences draw from the nostalgic recall and therefore were labelled as strong and light nostalgia. However, the third temporal frame falls somewhat outside of the nostalgia framework. Informants described experiences that happened lately, in their adulthood or reported them in such a way that the experiential content could not be easily labelled as nostalgic (e.g., 236, 294, 301, 309, 310, 337 and 398). We call this third temporal frame of recalled experiences the recent past. An informant described an all-terrain vehicle trip in the autumn of 2014 (444) and another informant wrote about returning home from a hiking trip last night just before writing and submitting his memories (399). These informants indicated that other people participated, but no detailed description was provided which, in contrast, would be typical for strong nostalgic experiences from the childhood. 
We are not suggesting that people do not encounter events that arouse nostalgic experiences or that they do not recall events drawn from their adulthood nostalgically. This can be a characteristic of the data: the informants just did not utilise a nostalgic tone in their writings when they described experiences encountered during adulthood. Writings about the recent past described everyday events were short and less detailed in writing, and they referred often to a repeating habitual or on-going practices:

I like to brew a few cups of strong coffee, pour it to the thermos, and add a little bit of milk and few saccharin. Close the cap and off to the library. It is good to slurp a few cups of coffee between reading the papers. (71)

It is noteworthy that some informants also referred to the future and to things, people or events that will be repeated. In the framework of nostalgia these lastly mentioned may be described with the term 'continuity' or long-standing nostalgia (Kessous \& Roux, 2008). In particular, descriptions of the recent past that direct to the future tend to refer to objects and events still accessible (Ryynänen et al., 2016). One's childhood experiences can be only lived again in memories whereas events such as brewing coffee and going to library are still accessible events. Reported discontinuous, single or first-time remembered consumption experiences took place in adulthood and were linked to memories from the recent past.

The informants' memories that may be labelled in terms of continuous or long-standing nostalgia (Kessous \& Roux, 2008) are related repeating practices and frequent events encountered in childhood and youth, but still encountered now and probably in the future as well:

[...] Are there any other [than Airam thermos] alternatives left? It is already hereditary, at the moment to the fourth generation. I wish good times for my father as well as for my grandchildren. I wish that I can share the same events with my younger grandchild, who just turned two months, as my father shared with me back then and with my daughter later and now her daughter! I wish to us also warm forthcoming trips during this fall and the coming winter as well! (194)

References to the future are based on on-going practices that will be actively maintained. We call this fourth temporal frame of recalled experiences practices for the future. Although these recalled experience descriptions draw from the past, we do not consider them to be a part of nostalgic recall. Events similar to those recalled can be experienced currently as the practices continued and reshaped. These kinds of consumption experience descriptions do not suit the classic definitions of nostalgia either (e.g., Holak \& Havlena, 1998; Holbrook \& Schindler, 1991). The descriptions of experiences related to consumption practices that project into the future show readers a way to transfer cultural knowledge to the next generations. In this case, with the help of an ordinary consumption object such as a thermos. References to the future describe the longevity of desired practices and wishes to keep up traditions and transfer them to loved ones.

\section{5 | CONCLUSIONS AND LIMITATIONS OF THE STUDY}

The informants of this study remembered the physical characteristics such as the materials, shapes, logos and colours of the thermoses through temporally structured experiences. They described what was typically kept in the bottles and other objects that were operated along with the thermoses. Memories also described the physical places, activities and practices of the recalled events in the context of free time and work life. Reported leisure experiences were related to everyday life, relaxing trips and outings mostly to the nature. Breaks and pauses involving a thermos were highlighted throughout the descriptions of both free time and work experiences. Frequently reported smell and taste memories were also often connected to these breaks.

As a result, four temporal frames were identified:

- Strong nostalgia describing experiences from one's childhood;

- Light nostalgia drawing from the youth age;

- The recent past highlighting the lately happened events and the recalled experiences encountered during adulthood and

- Practices for the future based on on-going consumption practices, willingness to maintain and transfer them to others in the future.

Strong nostalgia or the recalled experiences encountered during the childhood are vivid and emotional describing in detail meaningful others, special places and events. These experiences are well-covered in the extant literature on nostalgic consumption. Cherished childhood memories involving repeating and especial activities with others or singular bittersweet incidents (Muehling \& Sprott, 2004) seemed to be important to the writers. Meaningful others were mentioned in the context of strong or childhood nostalgic experiences as previous studies have shown (Davis, 1979; Holbrook, 1993; Holbrook \& Schindler, 1989; 1991; 1996; 2003; Kessous \& Roux, 2008; Ryynänen et al., 2016; Schindler \& Holbrook, 1993; 2003). The informants seemed to take part in the events controlled by the others in the writings that described experiences of strong nostalgia.

In terms of the extant literature, our slight departure comes with the temporal frame called light nostalgia. Experienced nostalgia tends to diminish in our materials during the youth years when an informant takes a more active role and the enchantment of childhood experiences slowly disappear. Informants tend to describe childhood and youth experiences differently, but they write quite similarly within these temporal frames. Both of these temporal frames incorporate continuous and long-term experiences, but the informants described experiences related to single events. Similarities between the temporal frames of nostalgia exist, but the central differences are organized around descriptions of childhood-youth, meaningful others-distant others (or missing other people), passive observer-active participant and pronounced emotional tone-minor emotional tone. Both temporal frames 
incorporated descriptions of memories that can be lived again only in one's memories in accordance with the currently dominant definitions of nostalgia.

The descriptions of experiences in the third temporal frame, the recent past, were contemporary. The closer to the present the memories are situated temporally, the more ordinary and embedded in the everyday practices of the informants the recalled experiences seem to be. Memories mostly described singular events. They were distanced and broad descriptions of experiences where the informant appeared as the main character of the story. Experiences from the recent past and from the adulthood in general are not as emotional as those related to nostalgic recall: there is a possibility to encounter similar events that arouse comparable experiences again whereas the events of nostalgic experiences are inevitably in the distant past. The fourth temporal frame, practices for the future, refers to maintaining the present family traditions in the future. These temporally structured experiences described repeating everyday practices and habits but also a wish to transfer traditions to next generations.

There are several findings in our study that align with the extant literature. First, the established definitions of nostalgia from the 1990 s are still useful in describing recalled consumption experiences as our research materials show. The Finnish writers described their childhood nostalgia involving a thermos as described in extant literature about consuming nostalgia. Second, the majority of consumers' writings embodied nostalgic elements and tone which could explain why nostalgic recall is well-addressed in the extant consumer research. Third, the definitions of nostalgia capture experiences involving ordinary everyday objects such as thermoses. Fourth, our study affirms that experiences of nostalgia are evident in consumergenerated written data and adds Finnish consumers to this larger body of research.

This article extends understanding of consumers' temporally framed recalled experiences beyond nostalgic theorizing. Although the majority of recalled consumption memories could easily be labelled as nostalgic, many of them described recent experiences with a contemporary tone. Our analysis identified three kinds of recalled experiences that could not be fitted easily into the classic definition of nostalgia. Although the descriptions can draw meaning from the far and nostalgic past, these informants' descriptions were different in terms of temporal frames but also in terms of their characteristics.

As in any research, our approach, research materials and the results have limitations. Recalled consumption experiences are stored in memory, which is a subjective recording device to file the past. Writing about one's memories requires the interpretation of the past which induced memorable experiences back then but are reflected on during the current act of recalling. The results are not statistically generalizable to any particular population as the materials were collected with convenience sampling from the Finnish people. The pool of participants probably consists of people who may be positively inclined towards and share experiences with thermoses. Although the research materials are place-bound and the thermos bottles as consumer products is focused, nostalgic recall described in the research materials supports the current findings of the consumer research.
The writing task and the possibility that other people's experiences were visible on the webpages could have steered the informants to recall certain kinds of experiences or encouraged them to report their memories with a coherent narrative style. Some of the informants also tended to write about one event and the related experiences, while others shared several events and experiences. Biographical writings were typically constructed into a narrative form starting from childhood and ending to the present. The majority of the memories was also from the childhood or adolescence years.

In the future research, it would be beneficial to seek more detailed information: socio-demographic information would be helpful in more specific content analysis, as well as, information about when remembered events took place, how the informants explain or reflect on the meanings of their experiences and why and how they chose to reflect an experience as they did. Ordinary everyday products inducing special and therefore memorable experiences seem to be worth closer examination. Based on our findings, future research could shed light to interactions between culture-specific materiality and the related recalled consumption experiences.

\section{ACKNOWLEDGMENTS}

We are very grateful to anonymous referees for their helpful comments, which improved our article substantially. This work was supported by the Foundation for Economic Education (Finland, grant number 10-5611).

\section{ORCID}

Toni Ryynänen (iD http://orcid.org/0000-0002-3710-5311

\section{REFERENCES}

Addis, M., \& Holbrook, M. (2001). On the conceptual link between mass customisation and experiential consumption: An explosion of subjectivity. Journal of Consumer Behaviour, 1, 50-66.

Arnould, E., Price, L., \& Zinkhan, G. (2002). Consumers. New York, NY: McGraw-Hill.

Autio, M., Collins, R., Wahlen, S., \& Anttila, M. (2013). Consuming nostalgia? The appreciation of authenticity in local food production. International Journal of Consumer Studies, 37, 1-5.

Baker, S., \& Kennedy, P. (1994). Death by nostalgia: A diagnosis of context-specific cases. Advances in Consumer Research, 21, 169-174.

Barrett, F. S., Grimm, K. J., Robins, R. W., Wildschut, T., Sedikides, C., \& Janata, P. (2010). Music-evoked nostalgia: Affect, memory, and personality. Emotion (Washington, D.C.), 10, 390-403.

Batcho, K. (2007). Nostalgia and the emotional tone and content of song lyrics. The American Journal of Psychology, 120, 361-381.

Belk, R. (1990). The role of possessions in constructing and maintaining a sense of past. Advances in Consumer Research, 17, 669-676.

Carú, A., \& Cova, B. (2003). Revisiting consumption experience: A more humble but complete view of the concept. Marketing Theory, 3, 267-286.

Carú, A., \& Cova, B. (2008). Small versus Big stories in framing consumption experiences. Qualitative Market Research: An International Journal, $11,166-176$ 
Carú, A., Cova, B., \& Pace, S. (2014). Combining qualitative methods in practice. Management Decision, 52, 777-793.

Chu, S., \& Downes, J. (2000). Long live Proust: The odour-cued autobiographical memory bump. Cognition, 75, B41-B50.

Dalli, D., \& Romani, S. (2007). Consumption experiences and product meanings: Pasta for young Italian consumers. In A. Carú \& B. Cova (Eds.), Consuming experience (pp. 65-78). London: Routledge.

Davis, F. (1979). Yearning for yesterday. A sociology of nostalgia. New York, NY: The Free Press.

Fuentenebro, F., \& Valiente, O. (2014). Nostalgia: A conceptual history. History of Psychiatry, 25, 404-411.

Hamilton, K., \& Wagner, B. (2014). Commercialised nostalgia: Staging consumer experiences in small businesses. European Journal of Marketing, 48, 813-832.

Havlena, W. J., \& Holak, S. L. (1991). The good old days: Observations on nostalgia and its role in consumer behaviour. Advances in Consumer Research, 18, 323-329.

Hepper, E. G., Wildschut, T., Sedikides, C., Ritchie, T. D., Yung, Y.-F., Hansen, N., ... Zhou, X. (2014). Pancultural nostalgia: Prototypical conceptions across cultures. Emotion, 14, 733-747.

Higson, A. (2014). Nostalgia is not what it used to be: Heritage films, nostalgia websites and contemporary consumers. Consumption Markets \& Culture, 17, 120-142.

Hirsch, A. (1992). Nostalgia: A neuropsychiatric understanding. Advances in Consumer Research, 19, 390-395.

Hirsch, A. (2006). Nostalgia, the odors of childhood and society. In J. Drobnick (Ed.), The smell culture reader (pp. 187-189). Oxford, UK: Berg.

Hirschman, E., \& Holbrook, M. B. (1982). Hedonic consumption: Emerging concepts, methods and propositions. Journal of Marketing, 46, 92-101.

Hofer, J. (1688[1934]). Medical dissertation on nostalgia (Trans. C. K. Anspach). Bulletin of the History of Medicine, 2, 376-391.

Holak, S. L., \& Havlena, W. J. (1992). Nostalgia: An exploratory study of themes and emotions in the nostalgic experience. Advances in Consumer Research, 19, 380-387.

Holak, S. L., \& Havlena, W. J. (1998). Feelings, emotions, and memories: An examination of the emotional components of nostalgia. Journal of Business Research, 42, 217-226.

Holak, S. L., Matveev, A. V., \& Havlena, W. J. (2007). Nostalgia in postsocialist Russia: Exploring applications to advertising strategy. Journal of Business Research, 60, 649-655.

Holbrook, M. B. (1993). Nostalgia and consumption preferences: Some emerging patterns of consumer tastes. Journal of Consumer Research, 20, 245-256.

Holbrook, M. B. (1995). Consumer research: Introspective essays on the study of consumption. Thousand Oaks, CA: Sage.

Holbrook, M. B. (2006). Consumption experience, customer value, and subjective personal introspection: An illustrative photographic essay. Journal of Business Research, 59, 714-725.

Holbrook, M. B., \& Hirschman, E. C. (1982). The experiential aspects of consumption: Consumer fantasy, feelings, and fun. Journal of Consumer Research, 9, 132-140.

Holbrook, M. B., \& Schindler, R. M. (1989). Some exploratory findings on the development of musical tastes. Journal of Consumer Research, 16, 119-124.

Holbrook, M. B., \& Schindler, R. M. (1991). Echoes of the dear departed past: Some work in progress on nostalgia. Advances in Consumer Research, 18, 330-333.
Holbrook, M. B., \& Schindler, R. M. (1996). Market segmentation based on age and attitude toward the past: Concepts, methods, and findings concerning nostalgic influences on customer tastes. Journal of Business Research, 37, 27-39.

Holbrook, M. B., \& Schindler, R. M. (2003). Nostalgic bonding: Exploring the role of nostalgia in the consumption experience. Journal of Consumer Behaviour, 3, 107-127.

Kauppinen-Räisänen, H., Gummerus, J., \& Lehtola, K. (2013). Remembered eating experiences described by the self, place, food, context and time. British Food Journal, 115, 666-685.

Kessous, A. (2015). Nostalgia and brands: A sweet rather than a bitter cultural evocation of the past. Journal of Marketing Management, 31, 1899-1923.

Kessous, A., \& Roux, E. (2008). A semiotic analysis of nostalgia as a connection to the past. Qualitative Market Research: An International Journal, 11, 192-212.

Kravets, O., \& Örge, Ö. (2010). Iconic brands. A socio-material story. Journal of Material Culture, 15, 205-F232.

Lowenthal, D. (1985). The past is a foreign country. Cambridge, UK: Cambridge University Press.

Meyers, O. (2009). The engine's in the front, but its heart's in the same place: Advertising, nostalgia, and the construction of commodities as realms of memory. The Journal of Popular Culture, 42, 733-755.

Muehling, D. D., \& Sprott, D. E. (2004). The power of reflection. An empirical examination of nostalgia advertising effects. Journal of Advertising, 33, 25-35.

Richins, M. (1994). Valuing things: The public and private meanings of possessions. Journal of Consumer Research, 21, 504-521.

Routledge, C., Wildschut, T., Sedikides, C., Juhl, J., \& Arndt, J. (2012). The power of the past: Nostalgia as a meaning-making resource. Memory (Hove, England), 20, 452-460.

Routledge, C., Wildschut, T., Sedikides, C., \& Juhl, J. (2013). Nostalgia as a resource for psychological health and well-being. Social and Personality Psychology Compass, 7, 808-818.

Ryynänen, T., \& Rusko, E. (2015). Professionals' view of consumers' packaging interactions-A narrative analysis. Packaging Technology and Science, 28, 341-355.

Ryynänen, T., Joutsela, M., \& Heinonen, V. (2016). My grandfather kept one of these tins on top of the bookshelf: Consumers recalled experiences involving packaging. Qualitative Market Research: An International Journal, 19, 4-26.

Schindler, R. M., \& Holbrook, M. B. (1993). Critical periods in the development of men's and women's tastes in personal appearance. Psychology and Marketing, 10, 549-564.

Schindler, R. M., \& Holbrook, M. B. (2003). Nostalgia for early experience as a determinant of consumer preferences. Psychology and Marketing, 20, 275-302.

Schmitt, B. H. (2010). Experience marketing: Concepts, frameworks and consumer insights. Foundations and Trends in Marketing, 5, 55-112.

Sedikides, C., Wildschut, T., Arndt, J., \& Routledge, C. (2008). Nostalgia: Past, present, and future. Current Directions in Psychological Science, 17, 304-307.

Sierra, J., \& McQuitty, S. (2007). Attitudes and emotions as determinants of nostalgia purchases: An application of social identity theory. Journal of Marketing Theory and Practice, 15, 99-112.

Spiggle, S. (1994). Analysis and interpretation of qualitative data in consumer research. Journal of Consumer Research, 21, 491-503.

Stern, B. B. (1992). Historical and personal nostalgia in advertising text: The fin de siècle effect. Journal of Advertising, 21, 11-22. 
Thompson, C. J., Locander, W. B., \& Pollio, H. R. (1989). Putting consumer experience back into consumer research: The philosophy and method of existential phenomenology. Journal of Consumer Research, 16, 133-146.

Tynan, C., \& McKechnie, S. (2009). Experience marketing: A review and reassessment. Journal of Marketing Management, 25, 501-517.

Underwood, R. (2003). The communicative power of product packaging: Creating brand identity via lived and mediated experience. Journal of Marketing Theory and Practice, 11, 62-77.

Vignolles, A., \& Pichon, P. E. (2014). A taste of nostalgia: Links between nostalgia and food consumption. Qualitative Market Research: An International Journal, 17, 225-238.

Wildschut, T., Sedikides, C., Arndt, J., \& Routledge, C. (2006). Nostalgia: Content, triggers, functions. Journal of Personality and Social Psychology, 91, 975-993.
Zarantonello, L., \& Luomala, H. (2011). Dear Mr Chocolate: Constructing a typology of contextualized chocolate consumption experiences through qualitative diary research. Qualitative Market Research: An International Journal, 14, 55-82.

Zhou, X., Sedikides, C., Wildschut, T., \& Gao, D.-G. (2008). Counteracting loneliness: On the restorative function of nostalgia. Psychological Science, 19, 1023-1029.

How to cite this article: Ryynänen T, Heinonen V. From nostalgia for the recent past and beyond: The temporal frames of recalled consumption experiences. Int J Consum Stud. 2018;42:186-194. https://doi.org/10.1111/ijcs.12398 